\title{
0796 INJURY PREVENTION IN SWEDISH AGRICULTURE
}

P Lundqvist*, C Alwall Correspondence: Department of Work Science, Business Economics and Environmental Psychology, Swedish University of Agricultural Sciences (SLU), P0 Box 88, Alnarp, S-23053, Sweden

\subsection{6/ip.2010.029215.796}

The aim of a national programme on injury prevention in Swedish agriculture is to reduce the number of injuries by $50 \%$.

During 2008-2009 there has been a planning phase. The concept is face to face interaction between educated supervisors (mainly farmers) in order to increase knowledge as well as changing attitudes and behaviours in relation to risks and injury prevention. They will work with concepts: (1) a three step focus group concept including development of action plans for each farm and farm family, (2) individual visits by supervisors on farms for interaction and action plan development and follow-ups, (3) farm walks with groups of farmers. All concepts will give the farmer/farm family support for identifying his/her own risks and ways of preventing injuries. The goal is to give the farm family motivation to handle their problems by themselves as an integrated part of farming. Special focus is given to children and senior farmers ( $>65$ years).

Almost 150 persons have been educated as supervisors. They have been given facts on injuries and injury prevention, but the focus was training of a pedagogic method called future workshop both during the course and as a working tool for them 


\section{IP Safety 2010 abstracts}

during their meeting with farmers. The mission as supervisors started in the end of 2009 and will be evaluated until the end of 2013 . The goal is to reduce the injuries by $50 \%$ and the vision is to reduce the fatal injuries by $100 \%$. 